\title{
Economia solidária: projetos e práticas
}

\section{Solidary economy: projects and practices}

\author{
Fernanda Henrique Cupertino Alcântara ${ }^{1}$
}

\begin{abstract}
Resumo
Este trabalho discute as diferenças e similitudes entre cooperativas, empreendimentos de Economia Solidária e associações. Aborda, também, os resultados de pesquisa que sugerem incoerência entre o projeto de Economia Solidária e as práticas verificáveis, além de chamar a atenção para as terminologias oriundas da análise de outros temas, equivocadamente sobrepostas aos fenômenos desta. Este trabalho pauta-se numa pesquisa bibliográfica ampla e conclui que muitos equívocos e oportunismos têm vitimado tanto a prática quanto a teoria sobre ES, promovendo um afastamento do projeto modelar da chamada doutrina cooperativista e dos princípios de ES.

Palavras-chave: Economia solidária. Cooperativismo. Projetos. Práticas. Racionalidade.
\end{abstract}

\begin{abstract}
This paper discusses the differences and similarities between cooperatives, enterprises of Solidary Economy and associations. It also discusses the results of research that suggests inconsistency between the project of Solidary Economy and verifiable practices, and draw attention to the terminology from the analysis of other issues that are ambiguously overlapping phenomena of this. This work is guided in a wide literature and concludes that many misconceptions and opportunism have victimized both the practice and the theory about ES, promoting a shift away from the design model called cooperative doctrine and principles of ES.
\end{abstract}

Keywords: Solidarity economy. Cooperatives. Projects. Practices. Rationality.

\section{Introdução}

Este trabalho tem o objetivo de pontuar elementos característicos das relações estabelecidas para o desenvolvimento da chamada Economia Solidária (ES), apresentando projetos elaborados por teóricos e formadores de políticas públicas, expondo pesquisas sobre o tema e parte do arcabouço conceitual tornado público até a presente data. Trata, também, de explicitar mecanismos e instrumentos analíticos formulados pela Sociologia Econômica (SE), os quais, consideramos compatíveis com a pesquisa em ES, ainda que o foco central não seja o método ou a abordagem adotados, mas sim o recorte. Por SE, entendemos o ramo da Sociologia que estuda as relações econômicas, em suas múltiplas formas, configurações, significados e relações sociais que, dele, fazem parte. Fundamentalmente, as pesquisas em SE tentam desmistificar os modelos econômicos que buscam explicar as ações de modo

\footnotetext{
${ }^{1}$ Socióloga e Advogada. Especialista em Direito Urbanístico. Mestrado e Doutorado em Sociologia pelo IUPERJ. Pósgraduanda em Direito e Processo do Trabalho e Direito Notarial e Registral na Universidade Federal de Juiz de Fora. E-mail: alcantaraconsultorias@gmail.com.
} 
individual, desconsiderando sua inserção num dado contexto social ${ }^{2}$. A apropriação que fazemos da SE diz respeito ao fato de que consideramos as cooperativas e, de um modo mais geral, a ES como formas de organização das atividades produtivas, financeiras, de prestação de serviços e consumo, que resultam de uma construção social, condicionada, consequentemente, pelas relações sociais e tudo o que a elas é inerente. São exemplos de elementos que interferem e caracterizam as relações sociais: a cultura, a política, a cognição, a história, as ideias e as ideologias. Por isso, temos abordagens variadas, tanto dentro da SE quanto do Neoinstitucionalismo (NI), primando e dando relevância ora a um ora a outro elemento ${ }^{3}$. Singer (2007) discute esses pressupostos sem, no entanto, fazer referência às teorias aqui citadas. Ele alega que não se pode negar a relação entre ES e cultura, visto que a primeira está sempre condicionada, imersa e imbuída nesta e por esta.

Para melhor compreensão deste argumento, dividimos este trabalho da seguinte forma: uma explicação sobre a ES, o Cooperativismo e o Associativismo, a trajetória histórica destes, conceituação e problemas diagnosticados em pesquisas sobre o tema.

Acreditamos que a ES pode ser compreendida de diversas formas. Podemos analisá-la, a partir da observação de suas relações econômicas e produtivas, como, também podemos nos dedicar a estudar apenas as relações de reciprocidade e solidariedade construídas em torno de cada projeto, incluindo-se aí as implicações políticas e sociais, para além da esfera econômica. Uma terceira possibilidade seria associar os dois aspectos gerais, incluindo-os como objeto de um mesmo projeto. $\mathrm{O}$ leque de alternativas, entretanto, não se restringe a essas três opções, mas nos restringiremos a elas, na análise aqui apresentada. Do ponto de vista da SE, podemos realizar as três análises ao mesmo tempo, já que as relações econômicas, necessariamente, envolvem formação de redes sociais e produtivas, além de aspectos sociopolíticos. Barbosa (2007) contraria essa perspectiva, uma vez que critica tal entendimento e afirma que existe uma "pseudoconcreticidade" com relação à ES, visto que não é autônoma frente ao capitalismo e, tampouco, é automaticamente democrática. Concordamos com as duas últimas afirmações, mas entendemos que as práticas cooperativas possuem/constituem uma "real concreticidade", tendo em vista que impõem a construção de arenas de decisão, a multiplicidade dos contatos e laços sociais, além da possibilidade de reencaixe que se concretiza em função dos "sentimentos" de pertencimento e segurança (ALCÂNTARA， 2005， 2008; DOMINGUES, 2002).

Neste trabalho, no entanto, associamos as possibilidades expostas, priorizando o aspecto da formação desses empreendimentos, como respostas públicas e políticas à ausência de geração de renda, mantendo, com isso, um caráter bastante pragmático com relação a essa temática. Em todo caso, não ignoramos as consequências políticas e sociais advindas da opção por esse formato de organização do trabalho, tanto positiva quanto negativamente. Para tanto, voltemos aos conceitos.

A ES é composta por empreendimentos caracterizados pela autogestão e pela solidarização de capital, quer sejam registrados ou não ${ }^{4}$. A adoção de uma postura pragmática, que não negligencia as influências ideológicas, só se justifica na relação

\footnotetext{
${ }^{2}$ Para a aplicação deste pressuposto em pesquisa sobre ES ver Freitas, Silva e Freitas (2009).

${ }^{3}$ Ver: Willianson, Douglass North (1995), Victor Nee e Paul Ingram (2001). Citamos o Neoinstitucionalismo (NI) ao lado da SE, pelo tema que coincidentemente ambos abordam, mas não temos a pretensão de ignorar os embates teóricos acirrados entre representantes dos dois grupos.

${ }^{4}$ Carvalho e Pires (2004, p. 198) argumentam que, formalmente, toda associação e toda cooperativa são autogestionárias, na prática é que as diferenças e particularismos aparecem.
} 
entre SE e ES, já que possibilita uma visão crítica acerca do objeto de pesquisa. Digamos, uma visão "de fora" sobre a ES, contrapondo-se a uma defesa acrítica de sua prática. Referimo-nos, principalmente, aos estudos sobre ES que teimam em "defendê-la a todo custo", partindo de dados supostamente científicos e escondendo o caráter político-ideológico do qual o tema se reveste 5 . Logicamente, existem estudos outros que defendem a ES como alternativa de geração de renda (esse, inclusive, é o nosso caso), sem, contudo, se envolver no "movimento de defesa pela defesa"6. Há que se ressaltar que a efetiva maioria dos que estudam o tema têm uma fundamentação consolidada a favor ou contra este fenômeno.

Mesmo admitindo-se o fato de que a ES contempla vários formatos organizacionais ${ }^{7}$, adotaremos o cooperativismo como modelo de referência para as questões aqui trabalhadas, por ser minimamente regulamentado pela legislação brasileira, incluindo a nova Lei de Cooperativas, de 2012. Isso não nos impede de reconhecer que a ES assemelha-se muito mais ao que se convencionou chamar "cooperativismo autêntico", distinguindose, consideravelmente, do que denominamos "cooperativismo tradicional", mas não nos autoriza a dizer que ambos não façam parte da ES ou que só o "cooperativismo popular" cumpre os pressupostos de "autenticidade". Benini (2004), por exemplo, entende existir uma separação entre ES e cooperativismo. Discordamos de tal opção, visto que o cooperativismo, embora possua tipos bastante variados, analiticamente, encontra-se dentro de um movimento maior que é a $\mathrm{ES}^{8}$. Além disso, o autor citado equipara associação a cooperativas, o que, no caso brasileiro, é praticamente impossível, principalmente devido à função e composição jurídica e organizacional inerente a cada uma. A terminologia Economia Social englobaria essa definição, mas, como o próprio autor afirma, ela é própria ao contexto europeu e está relacionada ao Welfare State e ao enfraquecimento da autogestão9. Contudo, uma diferenciação necessária e procedente diz respeito às "coopergatos" (que são as "falsas cooperativas") e às chamadas "cooperativas autênticas", isto é, aquelas que atentam e praticam os princípios do cooperativismo e autogestão ${ }^{10}$. Nesse sentido, Benini (2004), Lima (2008) e Piccinini (2004) relembram os casos de fraude, nos quais, as cooperativas de trabalho são usadas para mascarar uma situação de "renúncia" aos direitos trabalhistas. Retomaremos este assunto adiante.

Icaza (2004) afirma que a realidade brasileira demonstra um "universo contraditório e plural", no que tange às experiências de ES. De acordo com ela, da pluralidade de situações e características, podem ser vislumbrados quatro tipos diferentes de grupos: 1) empreendimentos cooperativos com traço predominantemente coletivo e solidário; 2) empreendimentos de caráter associativo, baseados na articulação e cooperação de produtores individuais; 3) empreendimentos de caráter familiar, com diversos níveis de solidariedade e cooperação; 4) empreendimentos com traço predominantemente empresarial competitivo. Essa tipologia leva em consideração: a) o processo de tomada de decisões; b) o perfil democrático; c) a distribuição de renda; d) a autonomia em relação aos agentes externos;

\footnotetext{
${ }^{5}$ Não negligenciamos a possibilidade de que alguns entendam essa postura, que denominamos pragmática, também de ideológica.

"Sobre críticas à tentativa de naturalização da ES e do "autoemprego", valendo-se de argumentos diferentes dos aqui apresentados, ver Barbosa (2007).

${ }^{7}$ Ver Gaiger (2006); Singer (2000).

${ }^{8}$ Ver Singer (2000) e sua discussão sobre a ES como um conjunto de "pequenas empresas", ampliando o conceito de empresas para associações, cooperativas e empresas tradicionais. Além disso, a abordagem que faz sobre "cooperativas de ES", também, é importante para o debate a esse respeito.

${ }^{9}$ Ver Defourny (2009) e Wautier (2003).

${ }^{10}$ Ver Lima (2004, 2008); Piccinini (2004).
} 
e) a viabilidade e sustentabilidade. A diferença de comportamento dos membros de cada grupo, a qual determina essas distinções tipológicas, sua origem e consequências podem ser vislumbradas no trecho transcrito a seguir.

Todavia, formas de organização efetivamente solidárias e autogestionárias, pautadas pela democracia e autonomia decisória do conjunto dos trabalhadores são ainda muito incipientes na maioria das experiências. A trajetória de formação do grupo, o contexto local em que se desenvolve e as organizações que lhe servem de referência são fundamentais para compreender os avanços e limites nesse sentido. Assim, os empreendimentos do tipo 4, ligados à história e às práticas do cooperativismo tradicional, são os que apresentam maiores limitações, e sua própria lógica de funcionamento não contribui para qualificar a participação dos associados. $\mathrm{Na}$ outra ponta, os empreendimentos de tipo 1 são formados fundamentalmente por trabalhadores vinculados a lutas sociais, que geralmente antecederam a formação do empreendimento como tal; [...]. Entre esses trabalhadores, é possível identificar com clareza um discurso mais politizado, que visualiza os empreendimentos na perspectiva de construir caminhos para a transformação social em níveis mais amplos (ICAZA, 2004, p. 42).

Leite (2009) e Azambuja (2009), também, defendem entendimentos semelhantes que justificam tipologias e diferenciações. Para Leite (2009), revisitando os estudiosos do tema, existem três origens distintas para os empreendimentos que se enquadram no conceito de ES, quais sejam, os oriundos de: 1) empresas falidas; 2) da atuação de agências de fomento; 3) dos movimentos sociais. A autora atrela características particulares a cada um dos tipos mencionados, sendo que as empresas falidas relacionam-se à presença de dificuldade adaptativa pela mudança institucional abrupta que sofrem no processo e as agências de fomento são acusadas de gerarem dependência. Por último, os movimentos sociais seriam responsáveis por formarem empreendimentos genuinamente autogestionários. Para Azambuja (2009), existem três perfis de empreendimentos ligados à ES: $1^{\circ}$ ) de solidariedade; $2^{\circ}$ ) de assalariamento; $3^{\circ}$ ) de instrumentalização capitalista.

Embora envolva diferenciações quanto a características pertencentes a formas organizacionais variadas, essa discussão perpassa, ainda, a análise da distinção e semelhança entre ES e cooperativismo. Icaza (2004, p. 18) propõe que a ES diferencia-se das práticas cooperativas tradicionais dominantes até a década de 1970 e que estiveram em plena expansão até então; essa diferença decorre dos "processos, dinâmicas e espaço de atuação próprios”. Entretanto, embora distintos, entendemos a ES como uma forma de renovação do cooperativismo que revê os seus pressupostos e amplia a sua concepção original, não podendo ser dissociada deste.

O cooperativismo tradicional, por sua prática, apresenta-se fundamentalmente como uma opção de organização econômica e jurídica [...]. Em contrapartida, a economia solidária apresentase como um campo de construção de alternativas econômicas ao modelo dominante, alicerçadas em um discurso crítico transformador e em práticas solidárias e autogestionárias, muito próximas dos movimentos sociais. Sendo assim, sustentamos que esta, por suas experiências e por seu discurso, provoca a necessidade de discutir o próprio sistema cooperativo e desafia suas instituições, sua lógica organizacional e de poder (ICAZA, 2004, p. 22).

Na verdade, a citação acima trata da "prática" que a autora observa, não do projeto de ES e de cooperativismo. As diferenças fundamentais entre cooperativismo e ES podem ser assim resumidas: aquele é uma forma inovadora de organização jurídica do trabalho e do capital ${ }^{11}$; esta é um novo modo de ver o mundo do trabalho a partir de discursos e ações que revolucionam, inclusive, o cooperativismo tradicional. Além disso, as cooperativas tradicionais, geralmente, contam com muitos membros ${ }^{12}$, têm o controle centralizado por administradores contratados, são anteriores

\footnotetext{
${ }^{11}$ Carvalho e Pires (2004) lembram que, embora a ES não se resuma ao formato do cooperativismo, por questões de comercialização e escoamento do produto, os EES acabam constituindo ou migrando de seus mais diversos formatos para cooperativas.
} 
à década de 1980, embora, também, ocorram a partir desse período; as cooperativas fundadas mais recentemente tendencialmente são menores, o que facilita o controle pelos próprios sócios ${ }^{13}$, como, também, a participação mais ativa destes.

$\mathrm{Na}$ visão de propagadores e ideólogos do movimento, o cooperativismo aparece como uma das tantas respostas à crise estrutural do emprego, dividindo espaço com a informalidade e, mais recentemente, com o empreendedorismo individual formalizado (Singer, 2000). A resposta cooperativada diz-se não apenas econômica, como, igualmente, imbuída de aspectos outros capazes de auxiliar ou estimular a expansão de características autonomistas e democráticas ${ }^{14}$. Mas Almeida, Villar e Nakano (2004) lembram que o desemprego pode até impulsionar a criação de empreendimentos econômicos solidários (EES), mas ele é vivido em circunstâncias distintas por cada trabalhador, o que impede a garantia do desenvolvimento do modelo de cultura anteriormente citado, ainda que, muito provavelmente, a estrutura de sociabilidade seja alterada, tanto em circunstâncias mais brandas quanto em mais enfáticas.

Benini (2004), por sua vez, argumenta que o cooperativismo surge como reação à exploração do trabalho e à expansão industrial. Para acabar com a exploração, era necessário reconciliar o trabalhador com os meios de produção, impedindo a alienação. Como resultado lógico, tornou-se essencial alcançar a autogestão. Em outras palavras, a ES surge como uma proposta de combate à exploração e ao desemprego por meio da autogestão (SINGER, 1999). Mas, Gaiger (2003) vai além, ao argumentar que a ES permite o surgimento de uma nova "forma social de produção", dentro do modelo capitalista, tendo surgido como resposta à ausência de emprego e renda, além de alternativa transitória à opção de organização do trabalho. Outros autores são, inclusive, mais ousados e não entendem a ES como um "modelo de organização do trabalho", adquirindo, assim, o mesmo status teórico e programático de modelos que lhe opõem, como o fordismo, o taylorismo, o toyotismo ou o volvoísmo (Antunes, 1999; Ramalho e Santana, 2004). Estes autores colocam a ES ora como "semente de um novo modo de produção" (SINGER, 2000), ora no posto de modo de produção solidário, lado a lado com o capitalismo, o socialismo, o comunismo, o feudalismo e a antiguidade (MARX, 2008; NAGEM; ALCÂNTARA, 2009; SINGER, 1999).

\section{Trajetória Histórica}

Independentemente de quão distantes alguns teóricos concebam a ES do cooperativismo, a história dela é um prolongamento da história deste e, para compreendê-la, devemos remeter-nos a ele (SINGER, 1999, 2000, 2002). O cooperativismo remonta ao século XIX, quando supostamente surgiram as primeiras tentativas de combater os efeitos colaterais do modo de produção capitalista. Nas palavras de Singer (2002, p. 24), a ES:

[...] nasceu pouco depois do capitalismo industrial, como reação ao espantoso empobrecimento dos artesãos provocado pela difusão das máquinas e da organização fabril da produção. [...] Por isso, industriais mais esclarecidos começaram a propor leis de proteção aos trabalhadores. Entre eles, encontravase o britânico Robert Owen, proprietário de um imenso complexo têxtil em New Lanark. Em vez de explorar plenamente os trabalhadores que empregava, Owen decidiu, ainda na primeira década do século XIX, limitar a jornada e proibir o emprego de crianças, para as quais ergueu escolas. O tratamento generoso que Owen dava aos assalariados resultou em maior produtividade no trabalho, o que tornou sua empresa

\footnotetext{
${ }^{12}$ Geralmente, a bibliografia da área entende que a expressão "muitos membros" refere-se a mais de cem associados.

${ }^{13}$ Exceção feita às cooperativas de crédito, habitação e agropecuárias.

${ }^{14}$ As ideias de cultura autonomista, bem como sua conceitualização, estão presentes na tese de doutorado de João Roberto Lopes Pinto, IUPERJ (2004). Estão presentes, também, em Benini (2004), Gaiger (2003), Leite (2009) e vários outros autores que estudam esta temática.
} 
bastante lucrativa, apesar de gastar mais com a folha de pagamento. Owen tornou-se objeto de grande admiração e respeito, adquirindo fama de filantropo. Visitantes do mundo inteiro vinham a New Lanark tentar decifrar o mistério de como o dinheiro gasto com o bem-estar dos trabalhadores era recuperado sob a forma de lucro, ao fim de cada exercício.

De acordo com a Rede de Universidades das Américas para Estudos Cooperativos e Associativos - UNIRCOOP (2003, p. 6), as experiências cooperativas brasileiras surgiram simultaneamente à primeira experiência europeia, mundialmente conhecida como a Cooperativa dos Pioneiros de Rochdale. $\mathrm{O}$ trecho transcrito a seguir define claramente essa trajetória histórica, ao lembrar que: “A Colônia Tereza Cristina, fundada em 1847 no Paraná pelo médico francês Jean Maurice Faivre, sob influência das ideias de Fourier, inaugura o cooperativismo no Brasil". Schimidt e Perius (2003) confirmam essa assertiva e, também, lembram que o século XIX foi palco de outras experiências, tais como, a Cooperativa dos Empregados da Companhia Telefônica (1891), em Limeira/SP, e da Cooperativa do Proletariado Industrial em Camaragibe/PE (1894).

Contudo, Pedrini, Prim e Santos (2004) relatam que experiências anteriores a estas inauguraram o cooperativismo no Brasil, tendo, como exemplo, a Colônia chamada Falanstério do Saí, fundada em 1841, por Benoit Jules Mure e colonos franceses, no município de São Francisco do Sul, Santa Catarina. Outro exemplo é o da Colônia Cecília, fundada em 1890, por Giovanni Rossi e colonos italianos, em Palmeira, Paraná. Segundo estes autores, a primeira cooperativa de fato do Estado catarinense foi criada, em 1909, com o nome de COOPERPRIMA ${ }^{15}$.

É forte, na tradição gaúcha, a ideia de que os imigrantes desenvolveram o cooperativismo frente ao abandono do Estado. Nessa linha de raciocínio, alguns poderiam até afirmar que as políticas públicas desestimulariam a ação dos particulares, retirando deles sua capacidade empreendedora e condicionando a iniciativa à ação do Estado. Nos Estados do Rio Grande do Sul e em Santa Catarina, esse estímulo esteve muito ligado à Igreja e seus agentes, como os padres, por exemplo. Um dado importante é que, na experiência gaúcha, junto às cooperativas, eram criadas outras associações e grupos de ajuda mútua que, para nós, funcionaram como "elementos fixadores", os quais temos grande dificuldade de encontrar e desenvolver, na atualidade (Alcântara, 2008). Podemos aceitar tal afirmação, se considerarmos que, no Rio Grande do Sul, o cooperativismo e o associativismo encontram-se arraigados à cultura local. Icaza (2004), por exemplo, chega a chamar as associações de "espaço paralelo", com relação às práticas cooperativas. Esses "elementos fixadores", quando realizados anteriormente à instituição do cooperativismo, constituem o que denominamos "fontes de solidariedade" e "fontes de autogestão" (ALCÂNTARA, 2005, 2008).

O cooperativismo expande-se, pela primeira vez no Brasil, apenas a partir de 1930, em função do "[...] estímulo que o Poder Público destinou a este setor, identificando-o como um instrumento de reestruturação das atividades agrícolas" e da "[...] promulgação da lei básica do cooperativismo brasileiro, de 1932, passando a definir melhor as especificidades daquele movimento, diante de outras formas de associação" (UNIRCOOP, 2003). Esse dado contraria o diagnóstico mencionado anteriormente, se considerarmos apenas a trajetória a partir de 1930, pois, o cooperativismo iniciou-se devido à ausência do Estado, mas expandiu-se e fortaleceu-se, em parte, com a ajuda deste.

Nesse período, o cooperativismo brasileiro foi imposto "de cima para baixo", com o objetivo de promover o controle social (UNIRCOOP, 2003).

\footnotetext{
${ }^{15}$ Geralmente, os autores confundem empresa autogestionária com empreendimento cooperativo, o que, de fato, não procede, porque as duas são significativamente distintas, embora tenham características comuns, como vimos anteriormente.
} 
A relação com o Estado estimulou a expansão de cooperativas agrícolas de produção, de habitação e de serviços de tecnologia, ao mesmo tempo em que, também, por meio de lei, extinguiu por completo as cooperativas de crédito, com a Reforma Bancária de 1964. Apenas na década de 1980, o cooperativismo libertou-se da dependência do Estado, ao mesmo tempo em que se agravava um momento de crise social e econômica ${ }^{16}$. Até a década de 1980, o Estado era o principal financiador do cooperativismo agrícola e de crédito, mas esses recursos foram diminuindo com o advento da crise financeira. Além do problema de financiamento, as cooperativas sofreram uma tributação equivalente à das empresas mercantis, o que afetou a sua competitividade no mercado.

Constata-se, portanto, que, desde o seu primeiro impulso, o cooperativismo estava influenciado por "políticas públicas" e pelo marco legal ou regulamentação. Desde o surgimento do movimento cooperativista, houve a crescente necessidade de compatibilizar e garantir condições de experiência, por meio do "marco legal", haja vista, por exemplo, a promulgação da Lei das sociedades industriais e cooperativas, já em 1852, além, é claro, do discurso sobre a formação de redes, para fortalecer, individualmente cada empreendimento e, simultaneamente, a todos. Mas esse "incentivo" foi isolado, já que a Lei Brasileira $n^{0} 5.764$, de 1971 (Lei de Cooperativas), atualizada apenas pela Lei 12.690/2012, dificulta o desenvolvimento dos empreendimentos cooperativos, por não dar conta dos efeitos da dinâmica sociohistórica do próprio movimento. Em outras palavras, não houve um desenvolvimento expansivo nem atualizado do marco legal (SINGER, 2009). Tal regulamentação requer adequação urgente ao novo contexto sociopolítico e econômico, tanto para coibir e punir práticas fraudulentas, como para estimular práticas legítimas, sendo que, atualmente, não dá amparo para cumprir uma ou outra função de modo devido, embora muito se tenha avançado com a Lei 12.690/2012. As pesquisas realizadas em 2004, com empreendimentos no território do Estado do Rio Grande do Sul, dão um exemplo claro de como o marco legal foi atualizado, pois demonstram um aumento na quantidade de empreendimentos solidários autogestionários que possuem menos de 20 membros, ou seja, não se enquadravam no regime jurídico estabelecido pela Lei de cooperativas, a qual determinava este como o número mínimo necessário para a constituição de uma cooperativa, hoje, substancialmente reduzido (ICAZA, 2004). Em Santa Catarina, os EES, também, não se enquadravam nos requisitos formais impostos pela legislação vigente à época, o que implicava se manterem na informalidade e impedidos de gozarem dos benefícios que o registro na Junta Comercial, Receita Federal e Estadual conferem (como o acesso a linhas de crédito, comercialização com empreendimentos de outros Estados e municípios, conseguir selo de fiscalização sanitária e poder emitir nota fiscal, na condição de pessoa jurídica), o que lhes impossibilita de expandir seu potencial mercado consumidor, sem contar com os órgãos de fiscalização para atestar e dar garantia quanto à procedência e qualidade de produtos e serviços.

Sobre a relação entre imposição de práticas e sua efetivação, Singer (1999) argumenta que, se a proposta original do Socialismo não deu certo a partir da estatização dos meios de produção, deve-se pensar outras possibilidades, como o cooperativismo, por exemplo. Essa nova posição parte do princípio de que é dentro do próprio capitalismo que o socialismo concretizase. Segundo ele, o controle e centralização que o Estado exerceu sobre os empreendimentos, além da reforma política ter ocorrido de modo brusco, antes

\footnotetext{
${ }^{16}$ Com a CF/88, associações e cooperativas desvincularam-se do controle do Estado. Vide art. 5º, XVIII (BRASIL, 1988).
} 
da reforma social, impediu o fortalecimento destes empreendimentos e corrompeu o projeto socialista. Embora o autor aborde um contexto sociohistórico distinto da realidade brasileira, sua discussão pode ser apropriada para entender a participação do Estado, tanto no controle quanto no fomento do cooperativismo.

\section{Conceituação, Projetos e Práticas}

Como os efeitos perversos da reestruturação produtiva e do desemprego em massa ainda persistem, embora com nova roupagem e num contexto sociopolítico e jurídico bastante distinto, a discussão sobre o cooperativismo voltou à tona, sob o rótulo de ES, o que, à época, equivaleria a um modo de cooperativismo popular. A passagem a seguir ilustra bem essa afirmação.

É preciso refletir por um momento sobre o que significa a cooperativa popular, no contexto atual do Brasil, a abertura abrupta e descontrolada da economia às importações de mercadorias e de capitais ocasionou o desaparecimento de parte do parque industrial, comercial e de serviços e a desnacionalização de outra. Submetida à competição de países em que não existem direitos sociais como os conquistados pelos trabalhadores brasileiros e atingidas por recessões freqüentes, as empresas aqui sediadas reagem demitindo parte de seus empregados e tratando de substituir os restantes por prestadores contratados de serviços. [...] Nestas condições, boa parte dos assalariados foi conduzida à condição de desempregados crônicos ou, no estágio seguinte, a "inempregáveis" e toda essa gente procura sobreviver exercendo alguma atividade por conta própria individual ou em empresa familiar. (SINGER, 2003, p. 7).

Lógico que a perspectiva do desemprego foi afastada, de modo significativo, após a virada do século XXI, chegando, o Brasil, a alcançar a casa de 4,5\% no ano de 2010 (IBGE, 2009) e mantendo níveis baixos, mesmo face às graves crises europeia e norte-americana.

Como uma ampliação e prolongamento do cooperativismo, a ES reafirma a cooperação para o trabalho e a solidarização de capital. O conceito cunhado por Gaiger (2004b, p. 7) reafirma essa concepção, ao declarar que a ES reconcilia o homem com o trabalho, os meios de produção com a sobrevivência humana e que representa uma "opção ética" (GAIGER, 2006, p. 519).

Fundamentalmente, as pesquisas, das quais temos conhecimento, apontam que os EES, além de permitirem a sobrevivência econômica dos trabalhadores (pois agrega pela produção e/ou prestação de serviços), também, proporcionam a "produção de relações sociais, de símbolos, de valores”. (VIEITEZ; NAKANO, 2004, p. 139.). Assim como ocorre com o cooperativismo "autêntico", para se ter ES é necessário solidarização de capital e compromissos, somada à autogestão. É isso o que afirmam, Almeida, Villar e Nakano (2004, p. 174), no trecho transcrito a seguir:

Assim como se entende participação como conquista, o mesmo se pensa sobre autonomia, pois esta é antes de tudo autodeterminação, autogoverno. Nesta medida não pode ser vista de outra forma a não ser como exercício da liberdade e de capacidade de ação dotada de vontade, intencional. Entretanto, quando se trata de empresa solidária, não é possível imaginar um sujeito autônomo, independente do grupo do qual faz parte; a este conceito, é necessário incorporar o de solidariedade, como valor que rege a lógica da relação dos diferentes sujeitos, que ao viverem juntos, produzem a empresa solidária.

Mas, para chegar à autonomia e à autogestão, os cooperados devem negar mecanismos de dominação ou que verticalizem a tomada de decisão. Outra questão importante é o nível da democracia nos EES. Para Carvalho e Pires (2004, p. 200), nos EES, pode até ocorrer uma "falsa democracia", devido à ausência ou concentração de informações e conhecimentos. Essa consideração está presente, também, em várias outras obras, assim como a percepção de que o termo ES é controverso ${ }^{17}$.

Lima (2004) lembra que o dilema entre revolução ou reforma, pelo sistema cooperativo, remonta ao final do século XIX, tendo, aparentemente,

\footnotetext{
${ }^{17}$ Ver, por exemplo, Barbosa (2007). Embora esta autora não discuta as implicações ou correntes teóricas que fundamentam este conceito. Ela argumenta que utiliza esse termo porque ele foi adotado pela burocracia estatal.
} 
prevalecido a tese de que o cooperativismo é uma espécie de resistência ao movimento de exclusão e concentração inerentes ao sistema capitalista, ou uma alternativa de sobrevivência dentro desse sistema. Singer (1999) afirma que a ES é uma forma antagônica de organização da economia, em relação ao modo de produção capitalista, e o cooperativismo a forma mais radical de organização das atividades econômicas. Contrariando essa postura, para Razzeto (1997), a ES seria um processo constante e difuso de inserção de práticas econômicas solidárias no interior da estrutura econômica capitalista, construindo-se assim uma nova racionalidade econômica. Nessa mesma linha de pensamento; porém, trazendo outros elementos, Laville (2006) ressalta o caráter híbrido da ES mais do que uma forma de ruptura com a economia capitalista.

Essa discussão é acirrada, uma vez que vários exemplos de práticas cooperativas "renunciam" à possibilidade de resistência ao capitalismo e passam a fortalecê-lo ainda mais, retirando, inclusive, emprego e garantias trabalhistas de muitos trabalhadores (hoje esse quadro foi amenizado com a Lei 12.690/2012), ao mesmo tempo em que diminuem os custos das empresas tradicionais, ao terceirizar serviços para elas: Em outras palavras, o debate reacende a polêmica do século XIX sobre a existência de "cooperativas falsas" - como linha auxiliar do capital, e de "cooperativas verdadeiras" - que assumem o caráter autogestionário e solidário na perspectiva de emancipação dos trabalhadores. (LIMA, 2004, p. 46).

Consequentemente, não podemos ignorar e a maior parte da bibliografia da área já reconhece que existem vários tipos de cooperativismo, o que acaba, também, por respingar nos tipos de ES, sendo que os dois extremos são as "cooperativas autênticas" e as "falsas cooperativas."
Se, de forma ideal, a definição de 'empreendimentos econômicos solidários' aponta para traços constitutivos essenciais como solidariedade, mutualismo, cooperação e autogestão, na prática, essas características aparecem de forma muito diversa e em graus muito variados dentro das experiências analisadas. O fato de os empreendimentos terem caráter coletivo e serem organizados pela ação dos próprios trabalhadores não quer dizer que a solidariedade e a autogestão sejam centrais na sua dinâmica de estruturação e funcionamento. E isto tem a ver tanto com elementos de caráter estrutural - as condições e o contexto nos quais os empreendimentos surgem -, como com elementos de natureza política ou ideológica - a presença dos valores como orientadores das práticas dos participantes. (ICAZA, 2004, p. 36)

Outra questão verificada diz respeito às dificuldades encontradas pelas cooperativas para entrar no mercado e nele permanecer. Ao que tudo indica, a fase mais difícil é a da experimentação e, quando os empreendimentos superam essa fase, supõe-se que estejam mais aptos a sobreviver. Seus principais entraves são: déficit educacional e de capacitação em gestão cooperativa, além de qualificação técnica e profissional; a escala de produção, o capital de giro e a ausência de "tecnologia de ponta". Acrescentamos, a esses entraves, a falta de familiaridade com essa prática ${ }^{19}$. Tais problemas, em parte, são solucionados ou minorados com a formação de redes, as quais promovem a integração e articulação entre os empreendimentos. De acordo com Pedrini, Prim e Santos (2004, p. 93), “[...], redes embasam, fortalecem e impulsionam a economia solidária, dando-lhe maior possibilidade de construir a autogestão, a sustentabilidade futura, pois propõe a construção de políticas públicas de trabalho e renda, e busca ir além do já estabelecido, tecendo novas relações de trabalho, cidadania e um novo projeto societário".

Diante desse quadro, a ES deve ser um "projeto

\footnotetext{
${ }^{18}$ Ver também: Vieitez e Nakano, 2004.

${ }^{19}$ Ver, também, Carvalho e Pires (2004, p. 191), "os quais afirmam ser a familiaridade com a prática um fator determinante para a motivação inicial dos futuros cooperados e, também, é ela a responsável por causar nos trabalhadores a impressão de que a autogestão não é mais difícil do que as outras formas de organização do trabalho."
} 
de urgência" capaz de sanar o imediatismo da necessidade de sobrevivência, mas, também, reservar espaço para elementos que possibilitem um "projeto de futuro", criando um "novo subsistema dentro da economia" (ICAZA, 2004.).

Assim, ela cumpre seu papel de inserção social, já que uma parcela de seu público alvo é de trabalhadores excluídos do mercado de trabalho, e promove o desenvolvimento local e, também, porque não falar, "crescimento sustentável" (LARIO; RAJA, 2009; SINGER, 2000). Desse modo, realiza não apenas a necessidade de renda como promove novos laços de sociabilidade, o que, por sua vez, é usado como argumento para questionar a avaliação da ES, com os mesmos instrumentos usados para avaliar empresas tradicionais.

Ainda sobre o reconhecimento de que existem racionalidades e não apenas uma racionalidade, Araújo e Cianalli (2006) utilizam a teoria habermasiana, para discutir como a relação entre trabalho e sobrevivência pode engendrar situações supostamente racionais, que trazem consequências dramáticas ao mundo da vida, podendo ser até mesmo consideradas irracionais, em face disso. A pergunta por eles proposta pode ser amplamente aplicada aos EES: afinal, o que é racional na vida cotidiana? Por exemplo, segundo a leitura desses autores, Marx entendia que o capitalismo é racionalmente estruturado, mas nem por isso ignorava o fato de que os efeitos dele sobre o mundo vivido eram nitidamente irracionais. Dito de outro modo, as organizações sociais modernas são estruturadas de acordo com pressupostos racionais, os quais, também, atingem a vida cotidiana. Embora a racionalidade tenha surgido em oposição ao tradicionalismo, ela mesma tornou-se uma tradição (DOMINGUES, 2002). Aplicando as considerações de Araújo e Cianalli (2006) ao objeto deste estudo, cabe questionar se a ES é compatível com a racionalidade capitalista e se as cooperativas promovem ações econômicas e administrativas orientadas por uma racionalidade com relação a fins. Caso a resposta seja afirmativa, a maior parte da bibliografia na área critica essa postura, visto que a cooperativa funda-se em princípios que, em muitos momentos, são incompatíveis com a racionalidade de mercado, embora, também, visem à sobrevivência de seus associados. Então, não consiste em alternativa ao sistema e, sim, um ser estranho a este, tentando sobreviver, dentro dele, de forma híbrida. Por exemplo, a institucionalização do trabalho assalariado é vista como prova da expansão da racionalidade no mundo moderno, bem como o fato de o trabalhador ter sido transformado em um simples fator de produção. Os autores citados anteriormente acreditam que, tal como nos exemplos mencionados, a racionalidade alastrou-se por todas as esferas da vida e "transformou-se" num tipo disfarçado de dominação. A alternativa indicada seria, no caso das cooperativas, por exemplo, adotar uma racionalidade comunicativa exercida por meio das arenas decisórias e modos de organização do processo produtivo, sobrepondo-se à costumeira racionalidade instrumental. O que significa propor “[...] um paradigma centrado na argumentação e contra-argumentação dos indivíduos na linguagem, na fala, no consenso e na intersubjetividade posta na relação sujeito-sujeito. É uma razão que caminha à margem da condição instrumental e se baseia no entendimento mútuo de ouvintes sobre o mundo objetivo, social e subjetivo." (ARAÚJO; CIANALLI, 2006, p. 297).

$\mathrm{O}$ projeto que fundamenta o cooperativismo entende que o ser humano deve realizar-se plenamente, não devendo submeter-se à lógica da racionalidade instrumental imposta pelo mercado capitalista, mas acaba por sucumbir às práticas deste para se enquadrar em suas especificações na busca pela sobrevivência. Além disso, uma outra racionalidade, como a proposta por Habermas, requer um público "qualificado" para se relacionar e participar de seus processos. Caso contrário, os autores afirmam que, com "[...] as regras do jogo estipuladas pelo mundo sistêmico, pela força da ideologia dominante, pela alienação decorrente desse processo, pela fraqueza das políticas 
alternativas, permanece a subordinação ao sistema capitalista em suas diversas feições: trabalho atípico, temporário, precário, terceirizado, quando não, escravo e infantil". (ARAÚJO; CIANALLI, 2006, p. 305). Sendo assim, argumentam que a irracionalidade segue fantasiada de racionalidade, para legitimar o sistema capitalista.

A esse respeito, Gaiger (2006) argumenta que a ES possui "vantagens comparativas"20 com relação aos empreendimentos tradicionais. Esse conceito permite rever a premissa e concepção de eficiência, além de formular uma perspectiva de racionalidade fundada na reciprocidade. De acordo com esse autor, a solidariedade e a cooperação precisam ser incorporadas à prática cotidiana, para que aumentem os fatores de eficiência. Os EES compensam a ausência de capital com o trabalho intensivo, ultrapassando as oito horas normais da jornada diária de trabalho ${ }^{21}$. Para os trabalhadores desses empreendimentos, o trabalho tem um outro significado, apesar de mais intenso, já que eles apresentam baixa capacidade de acumulação, instabilidade financeira e insolvência, com uma frequência bastante elevada. Em decorrência, o imediatismo e a urgência são características dos $\mathrm{EES}^{22}$.

\section{As vantagens comparativas ajudam a} ultrapassar essas dificuldades. Segundo Gaiger (2006), quando os trabalhadores têm identidade com o empreendimento, este alcança a "viabilidade social", o que, por sua vez, permite vencer a instabilidade e a insolvência. Outra forma de superar os entraves comuns a esse tipo de empreendimento é não permitir que ocorram diferenças nas condições objetivas entre os sócios no início da experiência, nem de distribuição do trabalho ou de interesses. Embora nem todos os EES sigam o princípio do igualitarismo, isto é, da remuneração por produtividade, geralmente, não admitem que a norma, "uma pessoa, um voto", seja descumprida, em razão da quantidade de cotas pertencentes a cada cooperado. Além disso, Gaiger (2006), também, afirma ser necessário que cada cooperado seja qualificado para atuar em todas as etapas do processo produtivo. A rotatividade de funções e tarefas de trabalho auxilia nesse sentido, porque a alternância de tarefas ajuda a socializar experiências e conhecimentos. Entretanto, devemos lembrar a diferença entre esta e a rotatividade dos associados, sendo que a última dificulta a consolidação de uma identidade do grupo. Pedrini, Prim e Santos (2004, p. 119) assinalam que a rotatividade funcional permite que os cooperados alcancem um conhecimento coletivo sobre o processo produtivo em sua totalidade, além de evitar lesões de trabalho, por esforço repetitivo, e não fazer distinções entre pessoas, devido ao cargo que ocupam. Como consequência, tanto o conhecimento quanto o comando são reiteradamente horizontalizados, mas a rotatividade funcional costuma ocorrer mais facilmente apenas em grupos homogêneos. Parece haver consenso quanto ao assunto. Icaza e Asseburg (2004) afirmam ser necessário promover um "saber coletivo dos trabalhadores", quanto à gestão e produção, criando os chamados "espaços formativos", e Gaiger (2006) entende que a "socialização do conhecimento" é um efeito positivo do trabalho solidário, o que acaba interferindo no nível de participação dos sócios.

As faixas de remuneração, também, não podem diferenciar-se muito. Como afirmamos anteriormente, os EES precisam constituir redes, para se fortalecerem, principalmente buscando

\footnotetext{
${ }^{20}$ Uma das vantagens comparativas dos EES é o ambiente participativo e democrático, quando este se efetiva. Por outro lado, uma das possibilidades de sobrevivência dos EES reside na capacidade criativa de que eles dispõem para "abrir" nichos de mercado.

${ }^{21}$ Carvalho e Pires (2004, p. 195) ajudam-nos a afirmar essa premissa, ao citarem que: "A maioria dos EES não possui grande aporte de maquinário e bens de capital, sendo a força de trabalho e o capital intelectual, os principais geradores de valor do EES", considerando os dados de uma pesquisa realizada no estado de Minas Gerais.

${ }^{22}$ Ver, também Asseburg e Gaiger (2007).
} 
o apoio do setor público, que poderá, inclusive, viabilizar assessoria em várias circunstâncias. Mas, como lembram Pedrini Prim e Santos (2004), para que a assessoria alavanque o empreendimento, em média, ela requer uma ação contínua por três anos. Os autores lembram, ainda, que, em contrapartida, os cooperados precisam desenvolver um comprometimento com o trabalho regular e, ainda que no início, isso não seja possível, os meios de produção precisam ir gradativamente pertencendo à cooperativa, visto que este tipo de dependência é fatal para os EES, além, é claro, da necessidade de dispor de capital de giro próprio.

É importante considerar que a concentração das decisões ocorre não apenas por autoritarismo e especialização funcional, mas, também, por desinteresse ou falta de participação dos demais membros, configurando o famoso caso do free rider $^{23}$. Carvalho e Pires (2004, p. 220) lembram, também, que existe uma diferença significativa entre participação formal e participação informal, de um lado, e o conhecimento coletivo, de outro, os quais dão conta de várias facetas dos EES. Inclusive, a autora relata que é interessante que os cooperados tenham algum conhecimento jurídico, para entenderem as implicações de suas ações e omissões. Mesmo porque, como dito anteriormente, a concentração de saber gera um tipo específico de dominação: "As compras e vendas, a contabilidade, os investimentos, entre outros, entregues à diretoria ou a um administrador profissional, muitas vezes se constituem em impedimento da autonomia do trabalho".

Lima (2004) fornece exemplos dessa pluralidade, ao estabelecer uma distinção entre o que denomina "cooperativas "pragmáticas" (grupo no qual se incluem as "falsas cooperativas", mas não apenas elas) e as "cooperativas 'defensivas"” (originadas a partir da massa falida de fábricas e do movimento de organização dos trabalhadores, como, por exemplo, a ES). Nos dois tipos, ocorrem dependência, principalmente quando estimuladas por políticas públicas, o que afeta o desenvolvimento de uma “cultura autogestionária". Não bastasse isso, Lima (2004), com base na obra de Webb e Webb (1914), argumenta sobre a possibilidade da "degenerescência das cooperativas", a partir do momento em que abandonam a autogestão em busca da eficiência e mais se aproximam da dinâmica concentrada e hierarquizada das empresas tradicionais. Resumindo, para ele, as cooperativas "pragmáticas" não se restringem às "falsas cooperativas", pois englobam, também, os empreendimentos que ignoram os princípios cooperativos e assentam-se exclusivamente na busca pela geração de renda e diminuição dos custos operacionais, podendo estar ou não associadas às políticas públicas.

Icaza e Asseburg (2004), por exemplo, lembram que, quando as cooperativas são usadas para operacionalizara terceirização, isso não compromete apenas os direitos trabalhistas, mas, igualmente, a autonomia e a autogestão. Em compensação, Piccinini (2004, p. 70) lembra que a terceirização permite a flexibilização das relações dentro das organizações, o que as desonera, melhorando suas performances no mercado competitivo. Mas a autora, também, não ignora o fato de que o discurso sobre a imposição da necessidade de flexibilidade pelo mercado traz consequências imediatas às formas de organização do trabalho e sobre as condições para a realização deste. Ainda, sobre esse assunto, Icaza (2004) reconstrói uma preocupação que, também, aparece em Alcântara (2003a, 2003b): a de que as cooperativas, para se tornarem empreendimentos bem-sucedidos de acordo com critérios do mercado, acabavam deixando para segundo plano a consolidação dos princípios cooperativos. Ironicamente, as experiências que

${ }^{23}$ Ver Mancur Olson (1999) e sua teoria da ação coletiva. 
Icaza (2004) analisou no Rio Grande do Sul reafirmaram essa preocupação, ao demonstrar que os empreendimentos mais autogestionários estavam em constante "fragilidade financeira" e dependentes de "organizações de referência". Já os empreendimentos que se afastaram desse princípio basilar para a prática cooperativa demonstravam maior eficiência e viabilidade econômica, porque, também, a quantidade de membros é significativamente maior e, com ela, tendencialmente é a capacidade de investimento pelo grupo $^{24}$. Consequentemente, parte das pesquisas sobre o tema indica que as "cooperativas empresariais" possuem uma "lógica empresarial" dissociada da "lógica solidária", faltando descobrir se é possível conciliar estas duas últimas.

Por essas e outras circunstâncias, a relação entre sindicatos, Ministério do Trabalho e do Emprego (MTE)/Superintendências Regionais do Trabalho (SRTs) ${ }^{25}$ e cooperativas nem sempre foi harmônica. Os sindicatos, contudo, ao perceberem que em determinados casos não era viável a luta pela manutenção dos empregos, mas sim a necessidade de encontrar novas alternativas de renda, começaram a estimular a formação de cooperativas e preocuparse em acumular conhecimento sobre essa prática, principalmente no que tange à qualificação e capacitação dos trabalhadores. Como bem lembram Icaza e Asseburg (2004, p. 58), “[...], apesar das divergências de posição entre os sindicatos, a iniciativa de organização dos trabalhadores desempregados em cooperativas foi uma saída encontrada para amenizar a situação de crise na região do Vale dos Sinos". Tanto o MTE quanto os sindicatos optaram, na última década, por combater apenas as "falsas cooperativas" e incentivar as demais. Mas os problemas não se resolvem apenas com tal atitude, existem outros pontos até mais complexos, como bem lembra Lima (2004, p. 56), ao afirmar que o tipo de organização do trabalho na cooperativa pode não diferir do que se observa na empresa tradicional, o que dificulta a consolidação de uma relação de pertencimento do trabalhador para com o empreendimento. Comumente, as pesquisas indicam que, para os trabalhadores, a "carteira assinada" é uma garantia, uma segurança que eles não conseguem substituir, quando assumem a propriedade e gestão de um negócio. Além de, pela responsabilidade assumida, ter que se sobrecarregar de serviço, aumentando seu tempo de trabalho e a preocupação com os resultados.

Por último, cremos ser o momento de pontuar algumas questões conceituais. Como tudo ainda é muito recente nessa área, equívocos terminológicos e fatos contraditórios são expostos ao grande público, sob o rótulo de "dados científicos", o que ajuda a confundir ainda mais esta temática. Em alguns casos, são questões localizadas, que não comprometem o restante da obra, configurando descuido ou mesmo desconhecimento. Mas, de qualquer modo, não se trata de preciosismo: a delimitação conceitual imprecisa ou equivocada compromete as interpretações relacionais daí derivadas. A literatura da área deveria estabelecer conceitos básicos, os quais, aparentemente, sequer são alvo de controvérsias, sem incorrer no risco de constituir doutrina sobre o assunto. Piccinini (2004), por exemplo, acredita que as cooperativas de trabalho, "por possuírem legislação própria", estão mais adequadas a atender à demanda por flexibilização do mercado através da terceirização. $\mathrm{O}$ que acontece é que o marco legal do cooperativismo brasileiro permitia, à época, que este contivesse um regime jurídico atrativo para a terceirização e, com ela, a precarização do trabalho. Hoje, esta realidade tende a ser modificada, com o advento da Lei 12.690/2012. Não obstante, alguns erros de enquadramento ocorrem, quando se considera que

\footnotetext{
${ }^{24}$ Essa, também, é a percepção de Vieitez e Nakano (2004, p. 168-170), ao analisarem EES no Estado do Rio Grande do Sul.

${ }^{25}$ Antigas Delegacias Regionais do Trabalho (DRTs).
} 
cooperativas são diferentes de empresas tradicionais porque têm "legislação própria", quando, na verdade, tem-se um regime jurídico específico, o qual é logicamente regulamentado por lei.

Outra questão é que cooperativa de trabalho não equivale, necessariamente, à terceirização, mas sim à prestação de serviços. Resta lembrar que não se pode confundir "falsas cooperativas" com cooperativas de trabalho, já que, no primeiro caso, não se trata do cooperativismo como um todo, mas sim de alguns empreendimentos de um ramo específico, qual seja, o das cooperativas de trabalho.

Além disso, as cooperativas não são representadas apenas pela OCB, no caso brasileiro, mas, também, por Centrais Sindicais (como a CUT) e movimentos sociais (como o MST, através da CONCRAB). Não podemos negligenciar o fato de que as diferenças regionais interferiram na consolidação do cooperativismo, principalmente no que tange à influência advinda com o fenômeno da imigração. Isso, também, ocorre quanto à estrutura de representação, convivendo, por exemplo, a OCB (tradicional) e CONCRAB (ligada ao MST). Para além desta questão, tem-se a reserva de representação que a Lei de Cooperativas faz à OCB, deslegitimando os demais tipos de representação.

Também, é recorrente, a confusão entre cooperativas e associações de trabalhadores, o que, na verdade, não se justifica. A primeira contém um regime jurídico que lhe autoriza produzir, prestar serviços e consumir nos termos especificados em lei. A segunda restringe-se à defesa dos interesses de seus associados. Na cooperativa, os membros associam-se, mas a relação jurídica é de cooperação econômica. Lógico que, no caso brasileiro, isso não é tão simples assim. São muitos, os casos em que associações exercem atividade produtiva, como meio de sobrevivência ou, até mesmo, como finalidade. É o caso, por exemplo, das APAEs, das associações de produtores rurais e assim por diante. Essa situação já está tão naturalizada que, até mesmo, editais e chamadas públicas do Estado, como o PAA - Programa de Aquisição de Alimentos, por exemplo, admitem a participação de associações e não apenas de cooperativas na concorrência.

Outro equívoco: cooperativas não oferecem "condições de empregabilidade" (ao menos não aos sócios), mas sim de renda. A própria Piccinini (2004, p. 75) lembra que o $\S$ único do artigo 442 da CLT determina: "Qualquer que seja o ramo de atividade da sociedade cooperativa, não existe vínculo empregatício entre ela e seus associados, nem entre estes e os tomadores de serviços daquela". Mas a autora peca, ao afirmar que dessa forma a lei considera esse trabalhador como "autônomo". O erro está no fato de que "cooperado" é um instituto diferente de "autônomo". Além disso, categorias como salário, emprego e férias remuneradas nada têm a ver com o cooperativismo, embora sejam usados pelos próprios cooperados em seu vocabulário cotidiano. Isso nos leva a considerar que analisar a cooperativa, tendo em mente o modelo assalariado de uma empresa tradicional, tal como o é montar uma cooperativa supondo-se que sua dinâmica corresponde à da empresa tradicional, não é apenas um mistake. Tal postura influencia os resultados de modo negativo, na medida em que distorce a estrutura institucional analítica disponível.

Outro ponto relevante é o de que a ES não pode ser confundida com o terceiro setor, já que ela encontra-se no segundo setor, o qual diz respeito às iniciativas privadas em si, embora não fale em lucros, mas tão somente em sobras. Novamente, retomamos a diferenciação entre Economia Social (que se enquadra no terceiro setor) e ES. Como lembra Jesus (2001, p. 207) a “[...], Economia Social abrange múltiplas realidades: são as empresas cooperativas, são as associações e são as organizações de ajuda mútua, segmento muito forte na Europa, denominado de sociétes mutualistes". A Economia Social abrange um conjunto muito amplo de experiências que engloba, inclusive, a ES. Contudo, não existe homogeneidade, quanto a tal diferenciação, sendo esta relativa ao caso brasileiro. A experiência da França, por exemplo, assemelha- 
se muito ao formato organizacional de associações brasileiras, tanto pelo tamanho das cooperativas quanto pelas características dos outros modelos de empreendimentos que, junto às primeiras, formam a chamada Economia Social, por exemplo, as Empresas Intermediárias (EI). Embora estes empreendimentos, no Brasil, não se assemelhem à ES, eles ajudam na expansão desta, agindo como "elementos fixadores" de um dado comportamento, ao torná-lo familiar e, consequentemente, institucionalizado.

\section{Considerações Finais}

Com base no exposto, podemos afirmar que muitos equívocos e oportunismos têm vitimado tanto a prática quanto a teoria sobre ES. As experiências, frente às contingências e externalidades, têm constantemente afastado-se do projeto modelar da chamada doutrina cooperativista e dos princípios de ES. A reflexividade nega a noção de doutrinamento e a corrompe, iniciando processos que ora aprimoram ora promovem a degenerescência do projeto inicial. Essa interpretação não diz respeito à reflexividade prática, mas sim a uma reflexividade profunda sobre as ações possíveis na realidade social à qual estão atrelados como agentes.

A multiplicidade de práticas remete à dimensão continental do território brasileiro e promove a emergência de novos projetos. Essa criatividade organizacional e institucional nega, contudo, a emergência da ES, como resposta às crises do mundo do trabalho, com solidez teórica e prática que precisam ser desenvolvidas. A ausência de consenso conceitual e teórico não justifica, por sua vez, os equívocos terminológicos encontrados em inúmeros trabalhos sobre ES e cooperativismo. O fundamento da argumentação dos autores que incorrem nestes equívocos resta prejudicado no instante em que as referências utilizadas são incoerentes e indevidas. Essas constatações não nos impedem de acreditar que a institucionalização da ES promoverá o assentamento de um arcabouço conceitual sólido, pautado num conhecimento menos precoce sobre o tema, produzido por pesquisadores experientes nesta seara e capazes de estruturar uma escola autônoma e reconhecida.

\section{Referências}

ALCÂNTARA, F. H. C. A institucionalização das redes cooperativas como modelos de organização do trabalho e de promoção do desenvolvimento econômico. 2003a. Dissertação (Mestrado ) - Instituto Universitário de Pesquisas, Universidade Cândido Mendes, Rio de Janeiro.

- A municipalização das políticas públicas de geração de renda e a institucionalização das práticas cooperativas: regulamentação e rotinização da prática. 2008. Tese (Doutorado) - Instituto Universitário de Pesquisas, Universidade Cândido Mendes, Rio de Janeiro.

As reformas legais e o processo de descentralização: aspectos jurídicos e políticos. Revista Sociologia e Política, v. 19, n. 39, p. 197-210, jun. 2011.

- Economia solidária: o dilema da institucionalização. São Paulo: Arte e Ciência. 2005.

Institucionalismo, racionalidade $\mathrm{e}$ solidariedade em cooperativas populares. In: HECKERT, S. Cooperativas populares: reflexões e perspectivas. Juiz de Fora: Ed. da UFJF, 2003b.

- Municipalização e políticas públicas: a regulamentação como projeto e a prática social como resposta. CSOnline, Juiz de Fora, ano 4, n. 10, p. 245 263, ago. 2010.

ALMEIDA, E.; VILLAR, M. E.; NAKANO, M. A participação efetiva e a conquista da autonomia. In: GAIGER, L. I. G. (Org.). Sentidos e experiências da economia solidária no Brasil. Porto Alegre, Ed. da UFRGS. 2004.

ARAÚJO, S. M.; CIANALLI, D. L. Trabalho e sobrevivência: o mundo da vida sob ameaça. Sociedade e Estado, Brasília, v. 21, n. 2, p. 289-313, 2006. 
ASSEBURG, H. B.; GAIGER, L. I. A Economia solidária diante das desigualdades. Dados, Rio de Janeiro, v. 50, n. 3, p. 499-533, 2007.

AZAMBUJA, L. R. Os valores da economia solidária. Sociologias, Porto Alegre, ano 11, n. 21, p. 282-317, jan. / jun. 2009.

BARBOSA, R. N. C. A economia solidária como políticas públicas: uma tentativa de geração de renda e ressignificação do trabalho no Brasil. São Paulo: Cortez, 2007.

BENINI, E. A. Políticas públicas e relações de trabalho: estudo sobre o processo e a natureza da denominada "economia solidária", enquanto política pública, a partir da investigação de alguns casos concretos. 2004. Dissertação (Mestrado) - Fundação Getúlio Vargas, São Paulo.

BRASIL. Constituição (1988). Constituição da República Federativa do Brasil.39. ed. São Paulo: Saraiva, 2012.

BRASIL. Lei № 5.764, de 16 de dezembro de 1971. Define a Política Nacional de Cooperativismo, institui o regime jurídico das sociedades cooperativas, e dá outras providências. Disponível em: <http://www. planalto.gov.br/ccivil_03/leis/15764.htm>. Acesso em: Acesso em: 20 nov. 2012.

Lei $N^{o}$ 12.690, de 19 de julho de 2012. Dispõe sobre a organização e o funcionamento das Cooperativas de Trabalho; institui o Programa Nacional de Fomento às Cooperativas de Trabalho - PRONACOOP; e revoga o parágrafo único do art. 442 da Consolidação das Leis do Trabalho - CLT, aprovada pelo Decreto-Lei no 5.452, de 1 o de maio de 1943. Disponível em: <http://www.planalto.gov. br/ccivil_03/_Ato2011-2014/2012/Lei/L12690.htm>. Acesso em: 20 nov. 2012.

CARVALHO, R.; PIRES, S. D. Para além dos aspectos econômicos da economia solidária. In: GAIGER, L. I. G. (Org.), Sentidos e experiências da economia solidária no Brasil. Porto Alegre: Ed. da UFRGS, 2004.
DEFOURNY, J. Economia social. In: CATTANI, A. D.; LAVILLE, J. L.; GAIGER, L. I.; HESPANHA, P. (Org.) Dicionário internacional da outra economia. Coimbra: CES, 2009.

DOMINGUES, J. M. Interpretando a modernidade. Rio de Janeiro: FGV, 2002.

FREITAS, A. F.; SILVA, M. G.; FREITAS, A. F. Por um sistema financeiro solidário na agricultura familiar: o sistema ECOSOL em Minas Gerais. Revista Cooperativismo y Desarrollo, Bogotá, v. 17, n. 95, 2009.

GAIGER, L. I. G. A economia solidária diante do modo de produção capitalista. Caderno $C R H$, Salvador, n. 39, jul./dez. 2003.

A economia solidária e o projeto de outra mundialização. Dados, Rio de Janeiro, v. 47, n. 4, 2004a.

A racionalidade dos formatos produtivos autogestionários. Sociedade e Estado, Brasília, v. 21, n. 2, p. 513-545, 2006

Sentidos e experiências da economia solidária no Brasil. Porto Alegre: Ed. da UFRGS, 2004b.

IBGE. Instituto Brasileiro de Geografia e Estatística. 2009. Disponível em: <http://www.ibge.gov.br/>.

ICAZA, A. M. S. Solidariedade, autogestão e cidadania: mapeando a economia solidária no Brasil. In: GAIGER, L. I. G. (Org.). Sentidos e experiências da economia solidária no Brasil. Porto Alegre: Ed. da UFRGS, 2004.

ICAZA, A. M. S.; ASSEBURG, H. B. Autogestão e viabilidade em cooperativas de calçado no Rio Grande do Sul. In: GAIGER, L. I. G. (Org.). Sentidos e experiências da economia Solidária no Brasil. Porto Alegre: Ed. da UFRGS, 2004.

JESUS, P. Inserção pelo trabalho e outras tendências da nova economia social na Europa. Ciências Sociais Unisinos, São Leopoldo, v. 37, n. 159, p. 205-234, 2001. 
LARIO, M. A.; RAJA, I. C. Crescimento sostenible de las presas agrárias espanolas: cooperativas versus sociedades capitalistas. Cooperativismo y Desarrollo, Bogotá, n. 95, jul. /dez. 2009.

LAVILLE, J. L. Ação pública e economia: um quadro de análise. In: FRANÇA FILHO, G. C. Ação pública e economia solidária: uma perspectiva internacional. Porto Alegre: Ed. da UFRGS, 2006.

LAVILLE, J. L.; FRANÇA FILHO, G. C. Economia solidária: uma abordagem internacional. Porto Alegre: Ed. da UFRGS, 2004.

LEITE, M. P. A economia solidária e o trabalho associativo. RBCS, São Paulo, v. 24, n. 69, fev. 2009.

LIMA, J. O trabalho autogestionário em cooperativas de produção. RBCS, São Paulo, v. 19, n. 56, 2004.

- Reestruturação industrial, desemprego e autogestão. Sociologias, Porto Alegre, ano 10, n. 19, p. 212-249, 2008.

LIMA, J. C.; MOURA, M. C. Trabalho atípico e capital social. Sociedade e Estado, Brasília, v. 20, n. 1, p. 103-133, 2005.

MARX, K. O capital: crítica da economia política. Rio de Janeiro: Civilização Brasileira. 2008. v. 1. (Livro I).

NAGEM, F. A.; ALCANTARA, F. H. C.; COELHO, F. M. G. Economia solidária: alternativa ao ou alternativa dentro do capitalismo? In: SEMINÁRIO SOBRE DIREITO COOPERATIVO E CIDADANIA, 2., 2009, Curitiba. Anais... Curitiba, 2009.

NEE, V.; INGRAM, P. Embeddedness and beyond: institutions, exchange, and social estructure. In: BRINTON, M.; NEE, V.(Ed.). The new institutionalism in sociology. Stanford: Stanford University Press, 2001.

NORTH, D. C. Five propositions about institutional change. In: KNIGHT, J.; SENED, I. (Ed.). Explaining social institutions. Michigan: The University of Michigan Press, 1995.

OLSON, M. A lógica da ação coletiva. São Paulo: EDUSP, 1999.
PEDRINI, D. M.; PRIM, L. F.; SANTOS, N. R. Apontando caminhos: a solidariedade na economia catarinense. In: GAIGER, L. I. (Org.). Sentidos e experiencias da economia solidária no Brasil. Porto Alegre: Ed. da UFRGS, 2004. p. 91-137.

PICCININI, V. Cooperativas de trabalho de Porto Alegre e flexibilização do trabalho. Sociologias, ano 6, n. 12, p. 68-105, 2004.

PINTO, J. R. L. Elogio à cooperação em tempos de crise. 2004. Tese (Doutorado). Instituto Universitário de Pesquisas, Universidade Cândido Mendes, Rio de Janeiro.

RAZZETO, L. Los caminhos de la economia solidária. Buenos Aires: Lumen-Hvmanitas, 1997.

REDE DE UNIVERSIDADES DAS AMÉRICAS PARA ESTUDOS COOPERATIVOS E ASSOCIATIVOS - UNIRCOOP. Regional Brasil. Panorama do cooperativismo: história, cenários e tendências. 2003. (Impresso).

SCHIMIDT, D.; PERIUS, V. Cooperativismo e cooperativa. In: CATTANI, A. D. (Org.). A outra economia. Porto Alegre: Veraz, 2003.

SINGER, P. Introdução à economia solidária. São Paulo: Fundação Perseu Abramo, 2002.

- Prefácio. In: HECKERT, S. (Org.). Cooperativismo popular. Juiz de Fora: Ed. da UFJF, 2003.

\section{9.}

. Uma utopia militante. Petrópolis: Vozes, . Economia solidária: democracia e conflitos entre iguais. Otra Economía, São Leopoldo, v. 1, n. 1, p. 14-16, 2007.

- Globalização e desemprego. São Paulo: Contexto, 2000.

- Economia solidária e políticas públicas: políticas públicas da Secretaria Nacional de Economia Solidária do Ministério do Trabalho e Emprego. Boletim Mercado de Trabalho: Conjuntura e Análise, Brasília, n. 39, p. 42-48, maio 2009. 
SWEDBERG, R. Max Weber e a idéia de sociologia econômica. Rio de Janeiro: Ed. da UFRJ, 2005.

VIEITEZ, C. G.; NAKANO, M. A economia solidária no Estado de São Paulo e os diferentes tipos de empreendimentos. In: GAIGER, L. I. G. (Org.). Sentidos e experiências da economia solidária no Brasil. Porto Alegre: Ed. da UFRGS, 2004.

WAUTIER, A. Economia social. In: CATTANI, A. D. (Org.). A outra economia. Porto Alegre: Veraz, 2003.

WEBB, S.; WEBB, B. Co-operative production and profit sharing. New Statesman, London, v. 2, n. 45, 1914. 